\title{
APLIKASI DISTRIBUSI ALAT KONTRASEPSI BERBASIS JAVA DESKTOP DAN MYSQL PADA DPPKB KABUPATEN SUKABUMI
}

\author{
Wawang Adi Darma ${ }^{1}$ ), Sofi Nurtalia ${ }^{2}$ ) \\ ${ }^{1,2)}$ Manajemen Informatika, Amik Citra Buana Indonesia Jl. KH. Ahmad Sanusi No.52, \\ Kota Sukabumi, Jawa Barat 43121 (0266) 225920 \\ e-mail: wawang@cbi.ac.id, sofi@cbi.ac.id \\ * Korespondensi: e-mail: wawang@cbi.ac.id,
}

\begin{abstract}
The Population Control and Family Planning Service (DPPKB) of Sukabumi district is one of the offices owned by the Sukabumi district government and one of its fields is engaged in the distribution of medical supplies / health facilities. Alokon / health facilities. In data processing and inventory of goods have not been computerized and there is no availability of applications that support to simplify the process of distributing goods alokon. DPPKB is one of the agencies that of course has used a computer system in carrying out work activities. This system emphasizes a set of elements contained in an organization, company, aspects, and different points of view according to the description of functions in matters relating to systems that have certain characteristics and characteristics. The results showed that computerized data processing can be processed easily using Java Desktop and MYSQL.
\end{abstract}

Keywords: DPPKB, Java Desktop and MYSQL.

\begin{abstract}
ABSTRAK
Dinas Pengendalian Penduduk dan Keluarga Berencana (BPPKB) kabupaten Sukabumi merupakan salah satu Dinas yang dimiliki oleh pemerintahan kabupaten Sukabumi dan salah satu bidangnya bergerak dalam pendistribusian Alokon/fasilitas kesehatan, Alokon/fasilitas kesehatan. Dalam pengolahan data dan persediaan barang belum terkomputerisasi dan belum adanya ketersediaan aplikasi yang menunjang untuk mempermudah pada proses pendistribusian barang alokon. BPPKB merupakan salah satu dinas yang tentu telah memakai sistem berupa perangkat komputer dalam menjalankan aktifitas kerja. Sistem ini menekankan sekumpulan elemen yang terdapat dalam suatu organisasi, perusahaan, aspek, dan sudut pandang yang berbeda sesuai dengan keterangan fungsi dalam hal-hal yang berkaitan dengan sistem yang memiliki ciri dan karakteristik tertentu. Hasil penelitian menunjukkan bahwa pengolahan data yang terkomputerisasi dapat diproses dengan mudah menggunakan Java Desktop dan MYSQL.
\end{abstract}

Kata kunci: BPPKB, Java Desktop dan MYSQL. 


\section{I.PENDAHULUAN}

Perkembangan dunia komputer yang semakin kompleks mendorong setiap individu atau kelompok mau tidak mau harus menerapkannya dalam segala aktivitas [1]. Disadari atau tidak setiap sistem yang ada seakan kurang lengkap ketika masih menggunakan model ataupun pengelolaan secara manual, disamping sangat banyak energi dan sumber daya yang akan terbuang, baik dari segi finansial yang tentunya menjadikan biaya lebih tinggi, maupun dari segi waktu yang akan memakan waktu lebih banyak [2].

Penerapan teknologi informasi telah menyebar hampir di semua bidang tidak terkecuali di bidang pendistribusian Alokon/fasilitas kesehatan pada Dinas Pengendalian Penduduk dan Keluarga Berencana (BPPKB) kabupaten Sukabumi [3]. Pendistribusian Alokon/fasilitas kesehatan dilakukan kepada seluruh fasilitas pelayanan kesehatan (puskesmas, klinik KB, dan poskesdes) yang berada di seluruh wilayah Kabupaten Sukabumi [4].

Dinas Pengendalian Penduduk dan Keluarga Berencana (BPPKB) kabupaten Sukabumi merupakan salah satu Dinas yang dimiliki oleh pemerintahan kabupaten Sukabumi dan salah satu bidangnya bergerak dalam pendistribusian Alokon/fasilitas kesehatan [5]. Dalam pengolahan data dan persediaan barang belum terkomputerisasi dan belum adanya ketersediaan aplikasi yang menunjang untuk mempermudah pada proses pendistribusian barang alokon [6]. BPPKB merupakan salah satu dinas yang tentu telah memakai sistem berupa perangkat komputer dalam menjalankan aktivitas kerjanya, tetapi dalam penggunaannya belum secara menyeluruh hanya untuk memanfaatkan beberapa hal saja, seperti pembuatan surat-surat dan laporan-laporan serta dalam pengolahan data yang masih menggunakan microsoft excel sehingga datanya masih belum tersusun secara rapi yang dapat menyebabkan terlambatnya pembuatan laporan karena langkah-langkah yang rumit.

\section{Landasan Teori}

Penelitian ini menggunakan metode kualitatif. Perreault dan McCarthy (2006: 176) "mendefinisikan penelitian kualitatif adalah jenis penelitian yang berusaha menggali informasi secara mendalam, serta terbuka terhadap segala tanggapan dan bukan hanya jawaban ya atau tidak. Penelitian ini mencoba untuk meminta orangorang untuk mengungkapkan berbagai pikiran mereka tentang suatu topik tanpa memberi mereka banyak arahan atau pedoman bagaimana harus berkata apa". 


\section{Metologi}

a. Teknik pengumpulan data merupakan langkah yang paling strategis [9].

b. Metode Observasi (Observation)

Kegiatan ini dimaksudkan untuk secara langsung melakukan pengamatan dan peninjauan yang dilakukan oleh penulis pada Dinas Pengendalian Penduduk dan Keluarga Berencana Kabupaten Sukabumi, sehingga memperoleh informasi yang jelas berkaitan dengan kegiatan yang dilakukan pada DPPKB Kabupaten Sukabum [10].

c. Metode wawancara (Interview)

Metode ini adalah pengumpulan data melalui tanya jawab yang dilakukan penulis kepada bagian staff pendistribusian Alat dan Obat Kontrasepsi DPPKB Kabupaten Sukabumi secara langsung [11].

\section{d. Metode Studi Pustaka (library Research)}

Metode studi pustaka digunakan agar mendapatkan sumber referensi yang baik berupa buku maupun artikel di internet untuk memperoleh bahan tentang perancangan program yang baik yang berhubungan dengan tugas akhir yang penulis buat [12].

e. Desain Pengembangan Sistem

Model SDLC (software Development Life Cycle) air terjun (waterfall) sering juga disebut model sekuensial linier (sequential linear) atau alur hidup klasik (classic life cycle). Model air terjun menyediakan pendekatan air hidup perangkat lunak secara sekuensial atau berurutan dimulai dari analisis, desain, pengkodean, pengujian, dan tahap pendukung (support) [8].

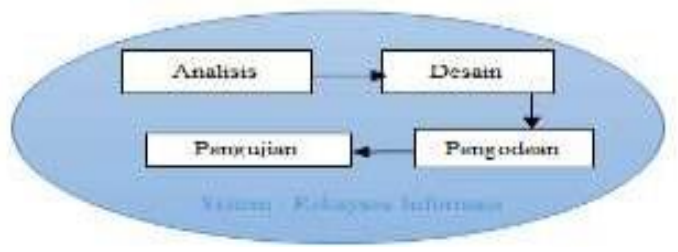

Gambar 3.1 Ilustrasi model waterfall

1. Analisis kebutuhan perangkat lunak

Proses pengumpulan kebutuhan dilakukan secara intensif untuk menspesifikasikan kebutuhan perangkat lunak agar dapat dipahami perangkat lunak seperti apa yang dibutuhkan oleh user. Spesifikasi kebutuhan perangkat lunak pada tahap ini perlu didokumentasikan [13].

2. Desain

Desain perangkat lunak adalah proses multilangkah yang fokus pada desain pembuatan program perangkat lunak termasuk struktur data, arsitektur perangkat lunak, representatif antarmuka, dan prosedur pengkodean. Tahap ini mentranslasi kebutuhan perangkat lunak dari tahap analisis kebutuhan ke representasi desain agar dapat diimplementasikan menjadi program pada tahap selanjutnya. Desain perangkat lunak yang dihasilkan pada tahap ini juga perlu didokumentasikan [14]. 
3. Pembuatan kode program

Desain harus ditranslasikan ke dalam program perangkat lunak. Hasil dari tahap ini adalah program komputer sesuai dengan desain yang telah dibuat pada tahap desain [16].

4. Pengujian

Pengujian fokus pada perangkat lunak secara dari segi logik dan fungsional dan memastikan bahwa semua bagian sudah diuji. Hal ini dilakukan untuk meminimalisir kesalahan (error) dan memastikan keluaran yang dihasilkan sesuai dengan yang diinginkan [15].

5. Pendukung (support) atau pemeliharaan (maintenance)

Tidak menutup kemungkinan sebuah perangkat lunak mengalami perubahan ketika sudah dikirimkan ke user. Perubahan bisa terjadi karena adanya kesalahan yang muncul dan tidak terdeteksi saat pengujian atau perangkat lunak harus beradaptasi dengan lingkungan baru. Tahap pendukung atau pemeliharaan dapat mengulang proses pengembangan mulai dari analisis spesifikasi untuk perubahan perangkat lunak yang sudah ada, tapi tidak untuk membuat perangkat lunak baru.

\section{Kelebihan Metode Waterfall}

Metode ini memungkinkan untuk departementalisasi dan kontrol. Proses pengembangan model fase one by one, sehingga meminimalisir kesalahan yang mungkin akan terjadi. Pengembangan bergerak dari konsep, yaitu melalui desain, implementasi, pengujian, instalasi, penyelesaian masalah, dan berakhir di operasi dan pemeliharaan.

\section{Kekurangan Metode Waterfall}

Kekurangan menggunakan metode waterfall adalah metode ini tidak memungkinkan untuk banyak revisi jika terjadi kesalahan dalam prosesnya. Karena setelah aplikasi ini dalam tahap pengujian, sulit untuk kembali lagi dan mengubah sesuatu yang tidak terdokumentasikan dengan baik dalam tahap konsep sebelumnya [18]. 
JURSISTEKNI (Jurnal Sistem Informasi dan Teknologi Informasi) Vol 2, No.3, September 2020: Hal 45 - 60

ISSN. P: 2715-1875, E: 2715-1883

\section{Hasil dan PEMBAHASAN}

\section{Analisis Dokumen Sistem Yang Sedang Berjalan}

Nama Dokumen input

BAPB (Berita Acara Penerimaan Barang), SBBK (Surat Bukti Barang Masuk) Sumber :

Gudang Provinsi

Tujuan

: Bendahara Barang

Proses

: Penerimaan Barang

Nama Dokumen output

SBBK (Surat Bukti Barang Keluar), SPMK (Surat Perintah Mengeluarkan Barang) Sumber

Distribusi

: Bendahara Barang dan Ekspedisi

Faskes Tingkat 1 / Kecamatan

Proses : Pengeluaran Barang

a. Flowmap sistem masuk barang yang sedang berjalan

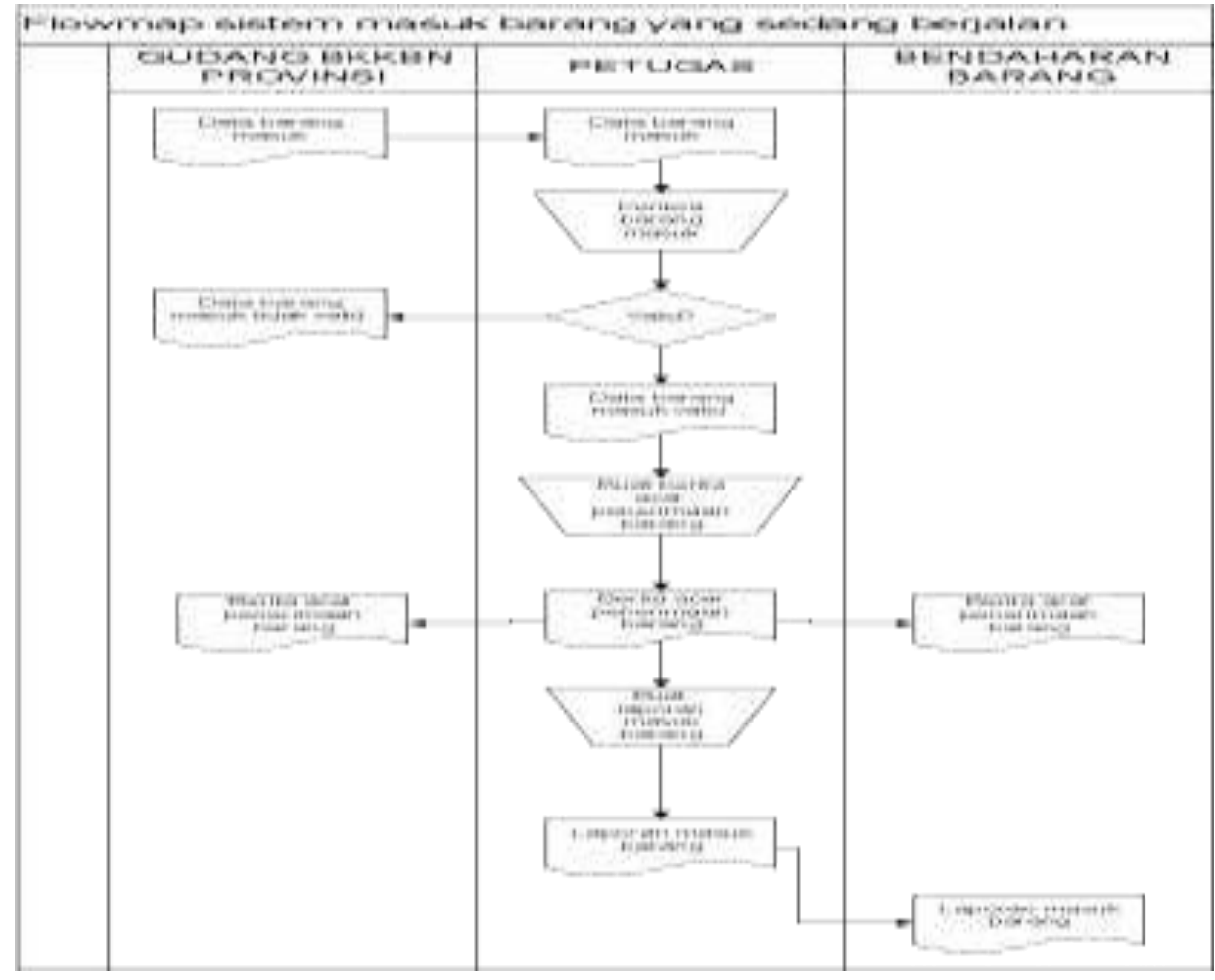

Gambar 4.1 Flowmap sistem masuk barang yang sedang berjalan 


\section{Analisa Prosedur}

a. Diagram Use Case yang sedang berjalan

Use case Diagram memperlihatkan hubungan antara aktor dan use case. Aktor dalam sistem yang ada yaitu Faskes 1, Bendahara barang dan Petugas yang akan berinteraksi dengan sistem. Boundary sistem memperlihatkan sistem yang sedang berjalan. Gambar diagram use case adalah sebagai berikut:

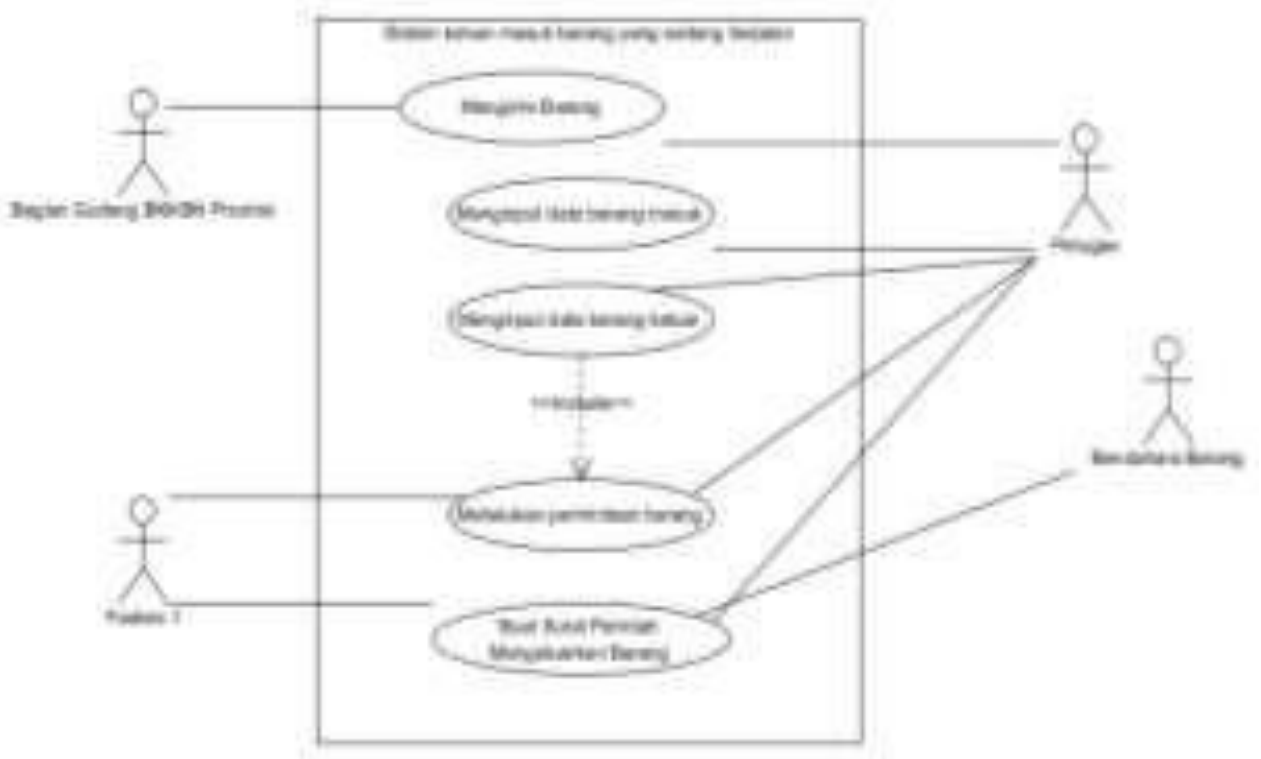

Gambar 4.2 Use Case Sistem yang sedang berjalan

b. Skenario Use Case yang sedang berjalan

Skenario use case ini memperlihatkan prosedur dan alur proses atau use case yang sudah digambarkan pada diagram use case sebelum nya. Skenario uses case seperti dibawah ini.

hTabel 4.1 Skenario Use case berjalan

\begin{tabular}{|c|c|}
\hline Aktor & Bistam \\
\hline $\begin{array}{l}\text { Faskes tingkat } 1 \text { atau kecamatan } \\
\text { mengajukan pemintaan alat } \\
\text { kesehatan, alat kontrasepsi (alkon) dan } \\
\text { alat non alkon }\end{array}$ & $\begin{array}{l}\text { Sistem manual melakukan pencatatan } \\
\text { pemintan }\end{array}$ \\
\hline $\begin{array}{l}\text { Bendahara menerma dan memeriksa } \\
\text { permintan barang. Jika valid maka } \\
\text { dibuat Surat Perintah Mengeluakan } \\
\text { Barang(GPMB) }\end{array}$ & \\
\hline $\begin{array}{l}\text { Petugas menbuat laporan pemintani } \\
\text { barang alkon atuu non alkon dan } \\
\text { diterina atau dilihat oleh Bendahara } \\
\text { Barang. }\end{array}$ & \\
\hline $\begin{array}{l}\text { Bagian gudang provingi menginimkan } \\
\text { barang }\end{array}$ & Sisten dilakukan pencatatan manual \\
\hline $\begin{array}{l}\text { Petugar menerima barang dan } \\
\text { membuat laporan peneriman barang }\end{array}$ & \\
\hline
\end{tabular}


JURSISTEKNI (Jurnal Sistem Informasi dan Teknologi Informasi) Vol 2, No.3, September 2020: Hal 45 - 60 ISSN. P: 2715-1875, E: 2715-1883

c. Evaluasi Sistem yang sedang berjalan

1) Sistem yang berjalan menggunakan pencatatan manual diperlukan input data permintaan barang alkon dan non alkon menggunakan aplikasi Java dan

MySql

2) Pembuatan laporan barang masuk dan barang keluar dilakukan secara manual dan akan dilakukan pelaporan per bulan.

\section{Analisa sistem yang diusulkan}

a. Flowmap Sistem masuk barang yang diusulkan

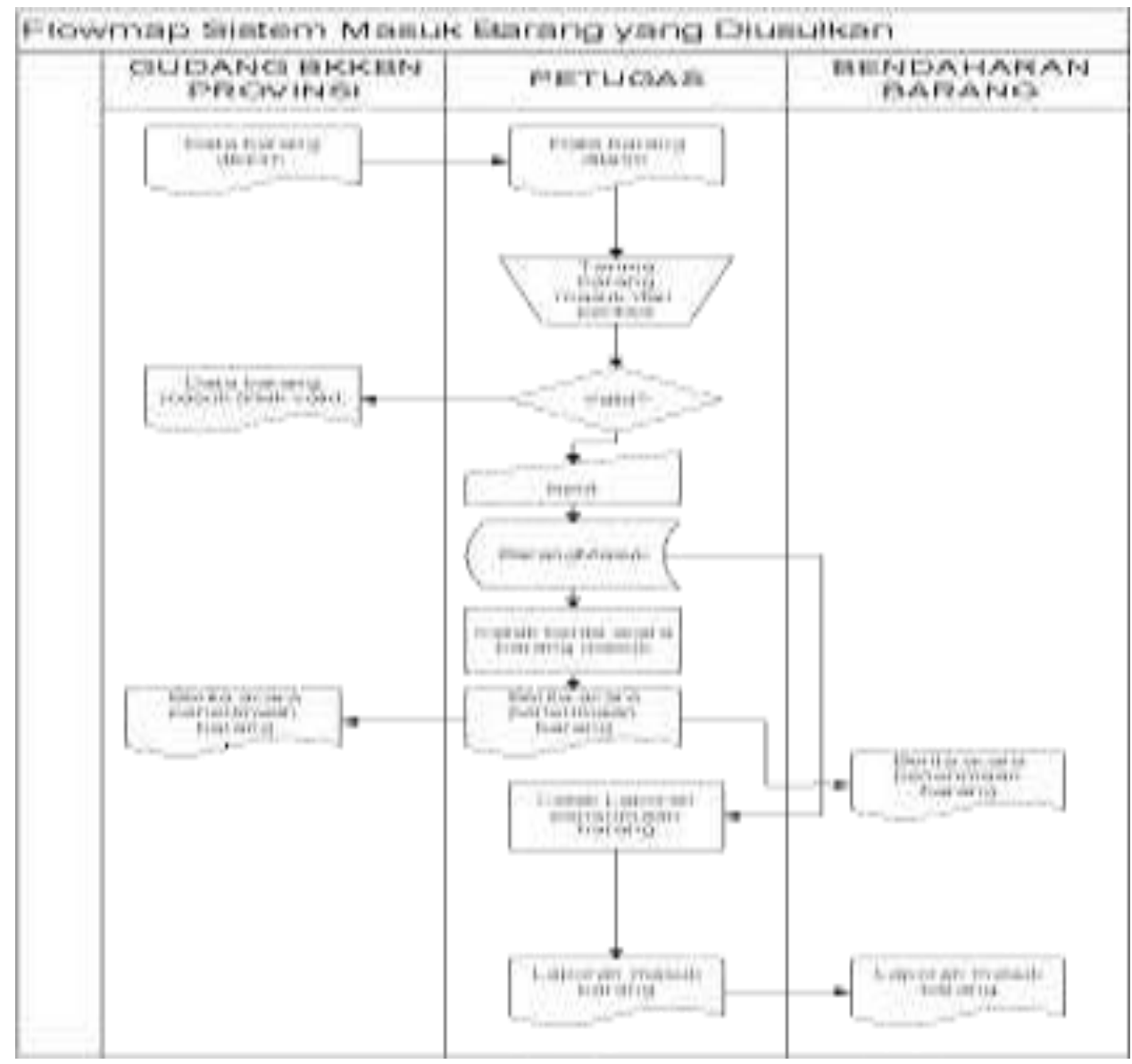

Gambar 4.3 Flowmap sistem masuk barang yang diusulkan 


\section{b. Diagram Use Case yang Diusulkan}

Berikut ini adalah gambar diagram use case untuk sistem keluar masuk barang alkon dan non alkon. Terlihat pada diagram sistem sudah menggunakan aplikasi komputer dengan petugas dan bendahara barang melakukan login untuk masuk ke program terlebih dahulu untuk melakukan setiap proses nya.

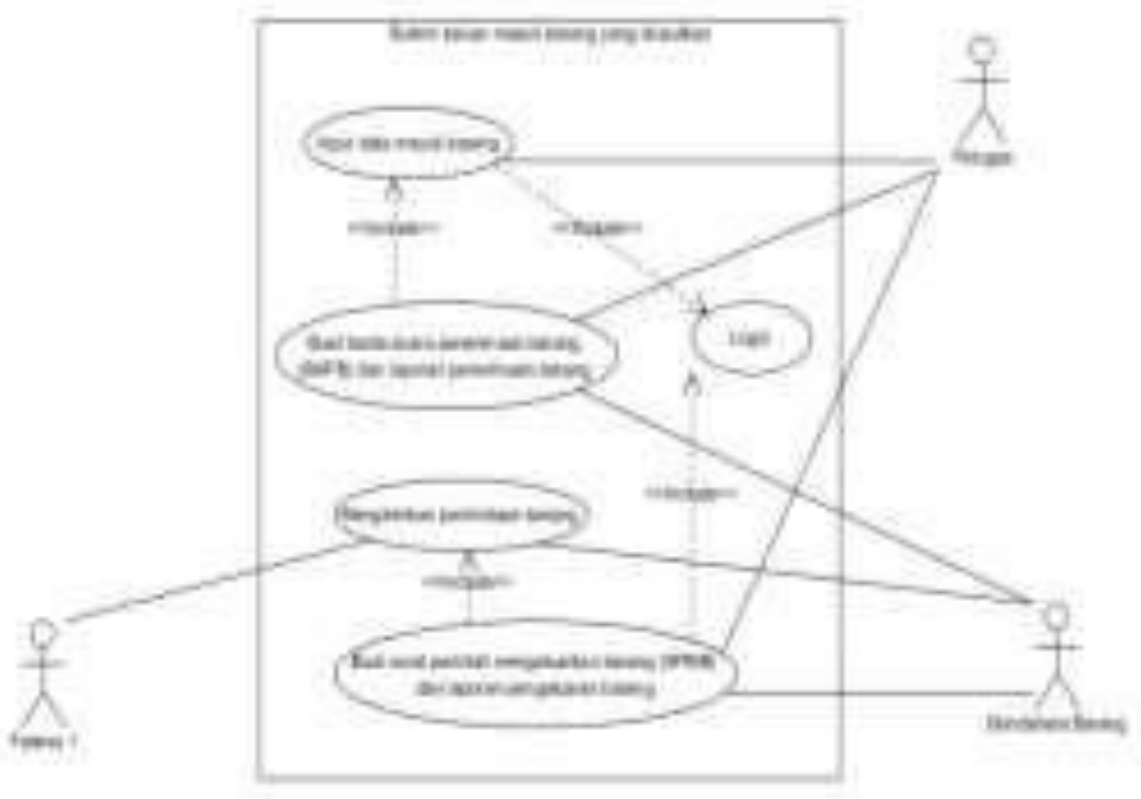

Gambar 4.4 Use case yang diusulkan

c. Skenario Use Case yang Diusulkan

Adapun skenario use case untuk sistem yang diusulkan ini memperlihatkan sistem yang sudah menggunakan aplikasi. Skenario ini terbagi menjadi skenario yang dilakukan oleh aktor dan respon sistem terhadap use case yang dilakukan oleh petugas.

Tabel 4.2 Skenario Use Case Yang Diusulkan

\begin{tabular}{|c|c|}
\hline Alitur & Sistain \\
\hline 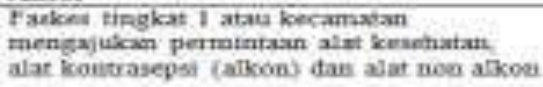 & \\
\hline \multicolumn{2}{|l|}{ 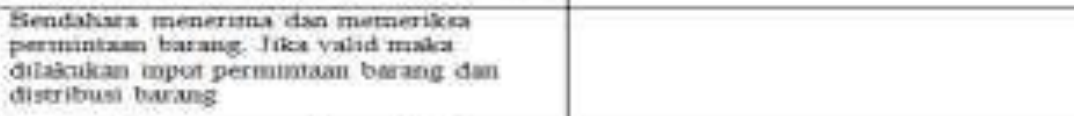 } \\
\hline \multicolumn{2}{|l|}{ 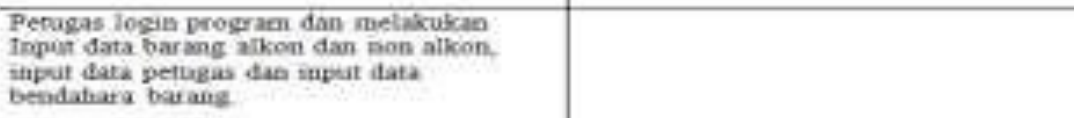 } \\
\hline & 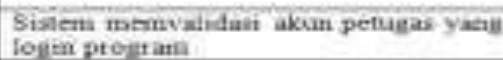 \\
\hline \multicolumn{2}{|l|}{ 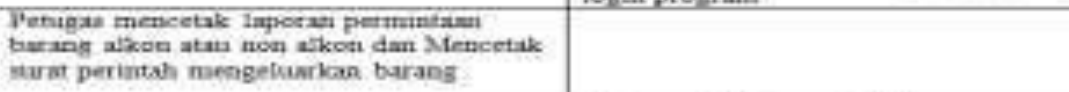 } \\
\hline & Starm melakisam cenck laporan \\
\hline 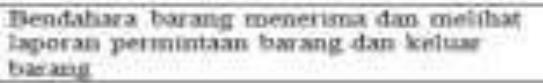 & \\
\hline
\end{tabular}




\section{d. Diagram Aktivitas}

Pada diagram ini terlihat bagaimana alur setiap proses yang dikerjakan oleh masing-masing entitas yaitu proses yang dikerjakan oleh faskes yang hanya mengirimkan permintaan barang. Petugas yang menginput ke dalam sistem dan sistem yang melakukan seluruh proses. Terakhir adalah aktor bendahara barang yang menerima seluruh laporan.

Diagram Aktivitas Sistem Masuk Keluar Barang secara umum

1) Diagram aktivitas proses login

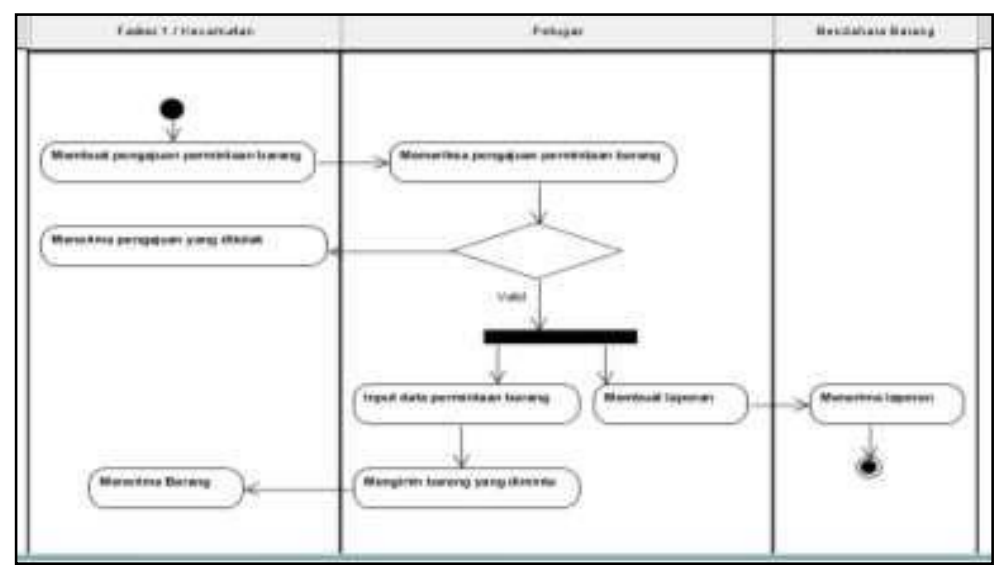

Gambar 4.5 Diagram Aktivitas seluruh proses

2) Diagram aktivitas proses input data barang keluar

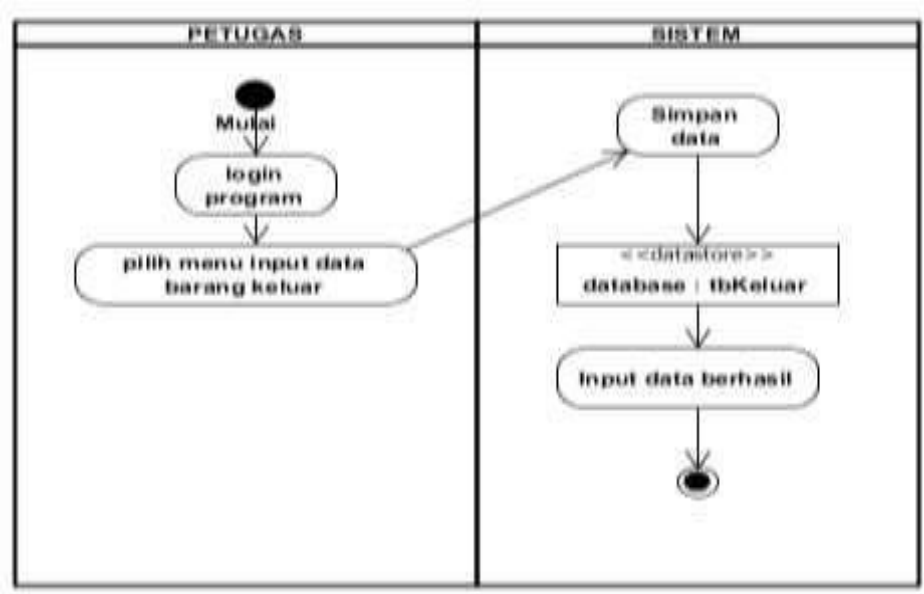

Gambar 4.6 Diagram aktivitas proses input data barang keluar 
JURSISTEKNI (Jurnal Sistem Informasi dan Teknologi Informasi) Vol 2, No.3, September 2020: Hal 45 - 60 ISSN. P: 2715-1875, E: 2715-1883

3) Diagram aktivitas proses input data permintaan barang

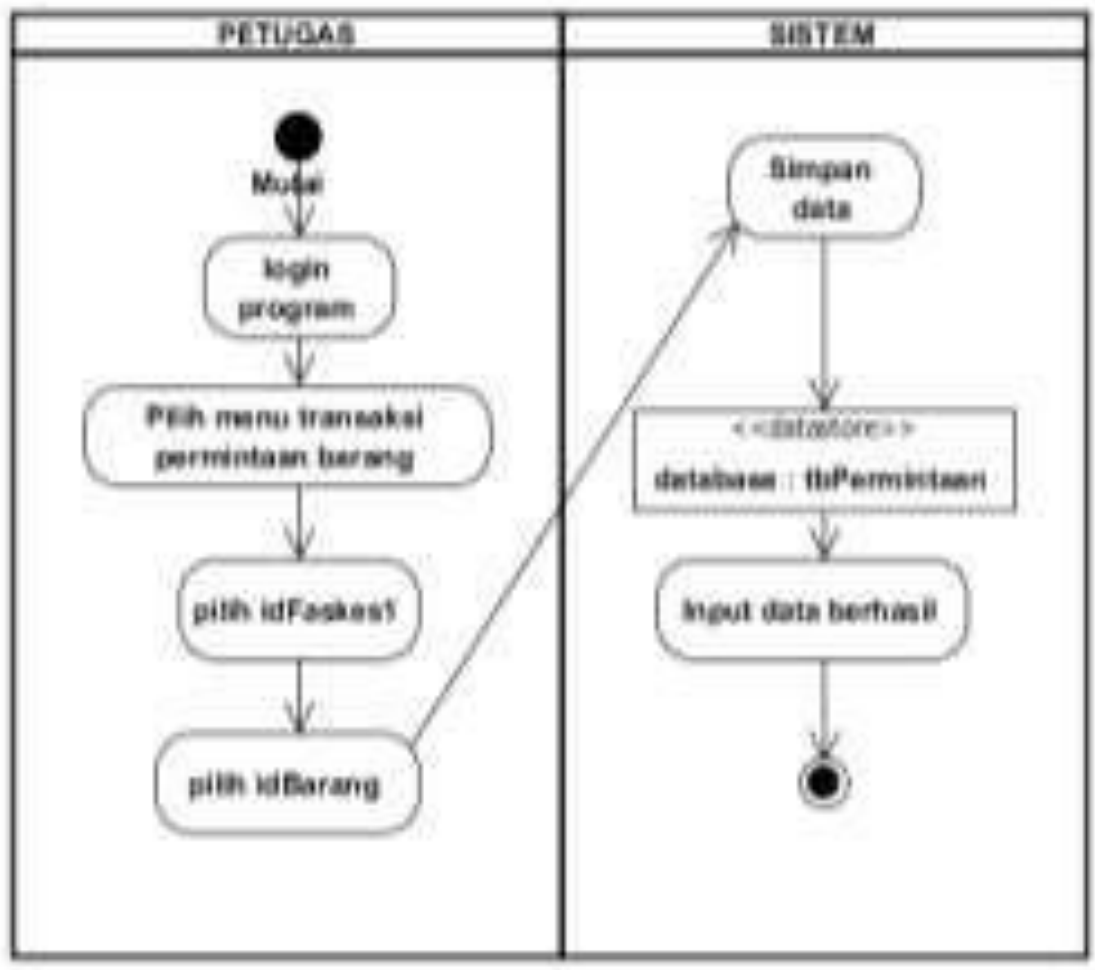

Gambar 4.7 Diagram aktivitas proses input data permintaan barang

4) Diagram aktivitas proses cetak Laporan, Surat perintah Mengeluarkan barang (SPMB) dan berita acara penerimaan barang (BAPB)

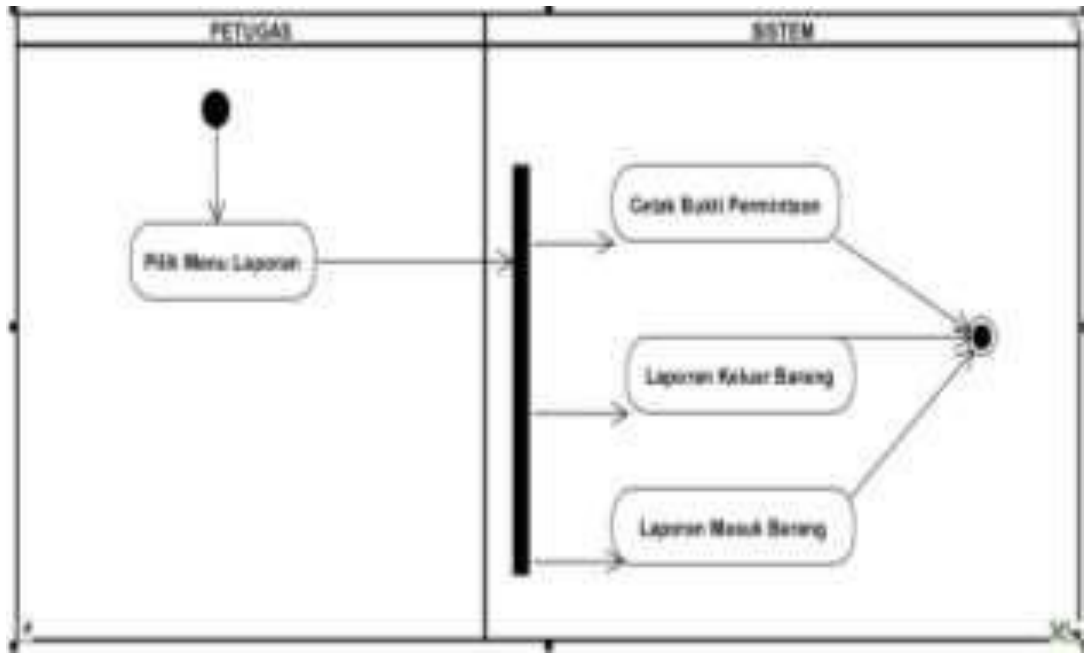

Gambar 4.8 Diagram aktivitas proses cetak laporan 
JURSISTEKNI (Jurnal Sistem Informasi dan Teknologi Informasi) Vol 2, No.3, September 2020: Hal 45 - 60

ISSN. P: 2715-1875, E: 2715-1883

e. Diagram Sekuen

Diagram sekuen memperlihatkan proses yang terjadi pada aplikasi program. Mula-mula aktor petugas melakukan login dan menginput data barang dan petugas. Selanjutnya melakukan input transaksi permintaan barang dan distribusi barang. Terakhir adalah membuat laporan yang bisa dilihat oleh bendahara barang.

Berikut adalah gambar diagram Sequence yang diusulkan.

1) Diagram Sequence Login program

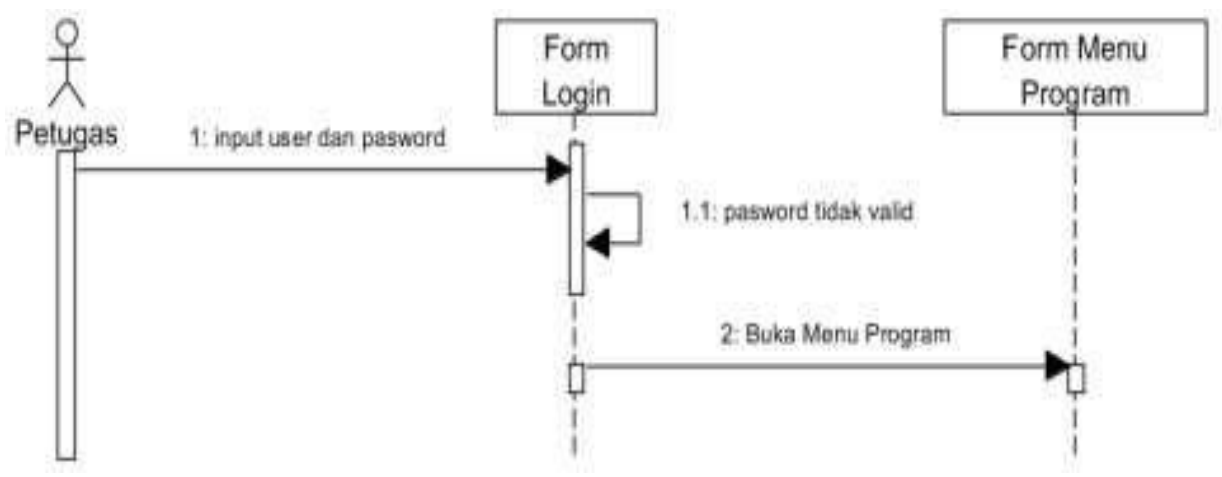

Gambar 4.9 Diagram Sequence Login Program

2) Diagram Sequence Input data barang

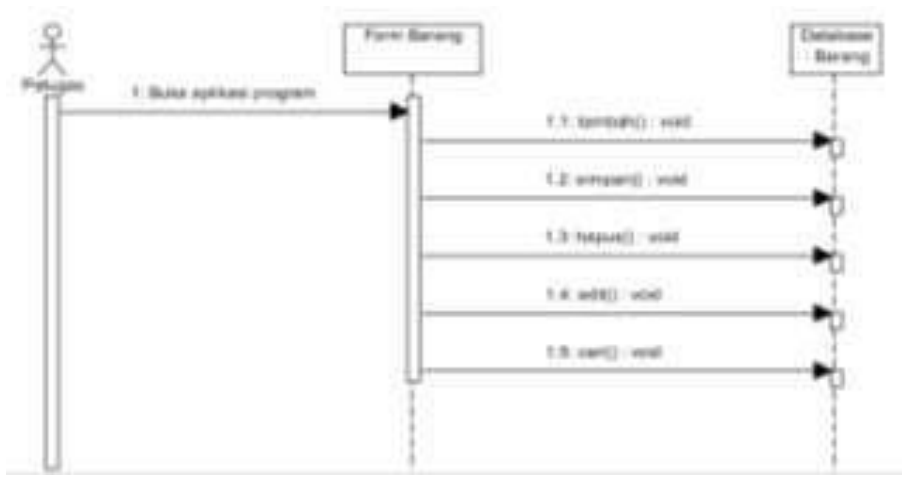

3) Diagram sequence Data permintaan barang

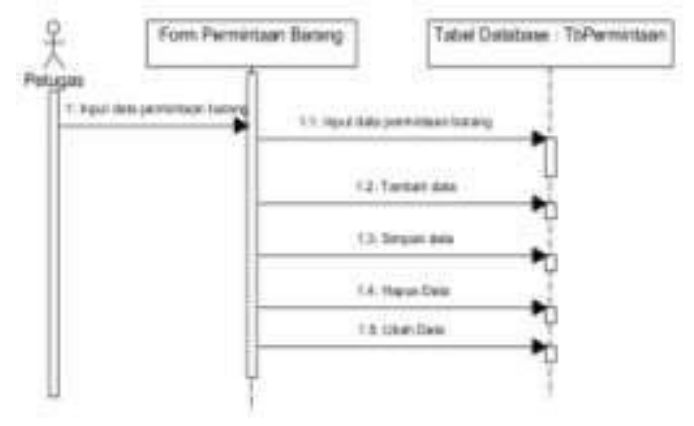

Gambar 4.10 Diagram Sequence Data Permintaan Barang 
JURSISTEKNI (Jurnal Sistem Informasi dan Teknologi Informasi) Vol 2, No.3, September 2020: Hal 45 - 60 ISSN. P: 2715-1875, E: 2715-1883

4) Diagram sequence data barang keluar

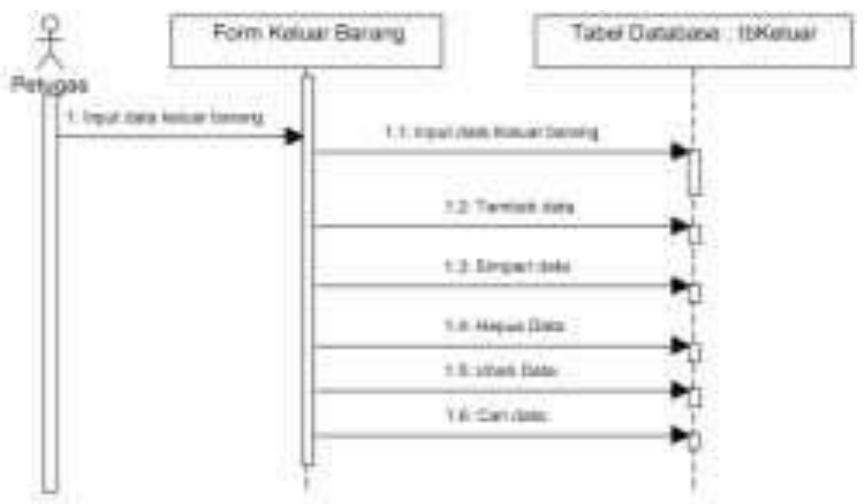

Gambar 4.11 Diagram Sequence Data Barang Keluar

\section{f. Diagram Class}

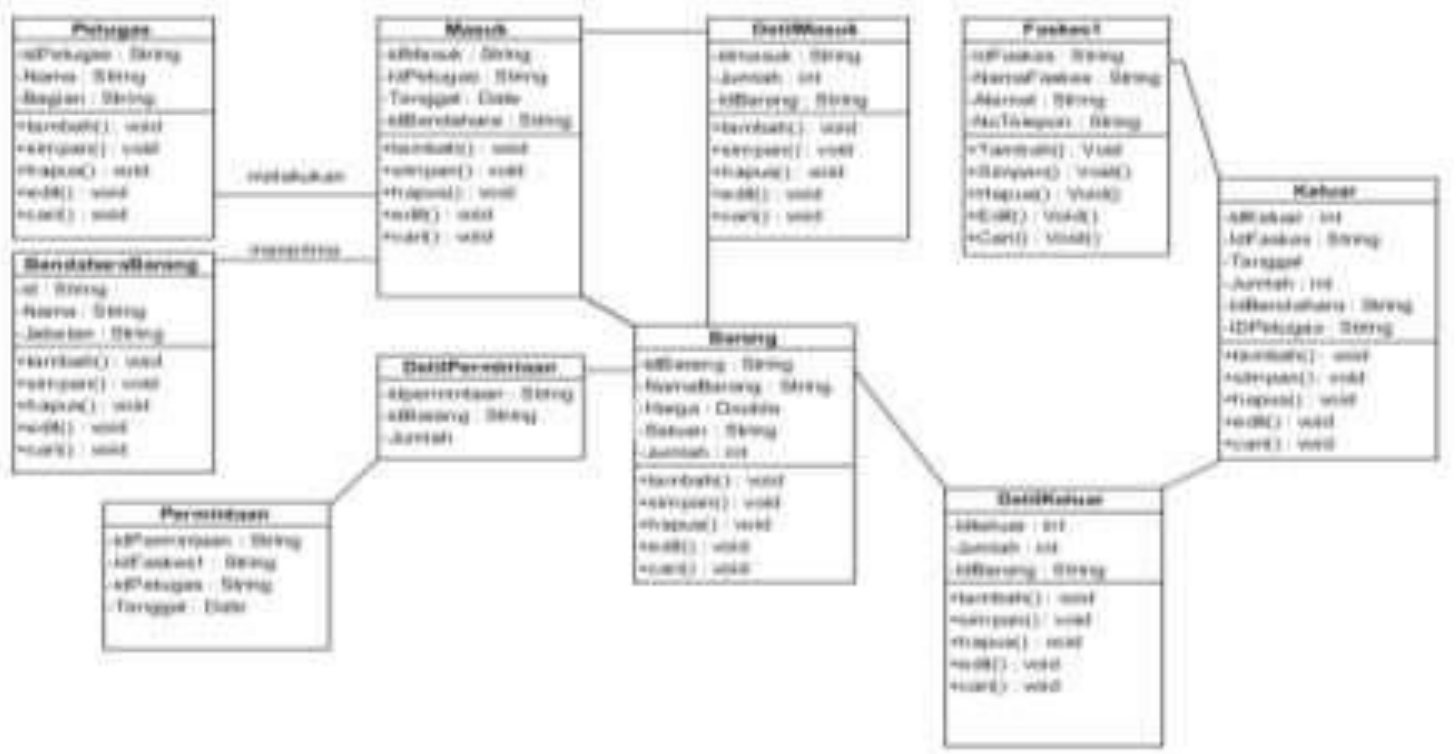

Gambar 4.12 Diagram Class 
JURSISTEKNI (Jurnal Sistem Informasi dan Teknologi Informasi) Vol 2, No.3, September 2020: Hal 45 - 60 ISSN. P: 2715-1875, E: 2715-1883

g. Diagram ER

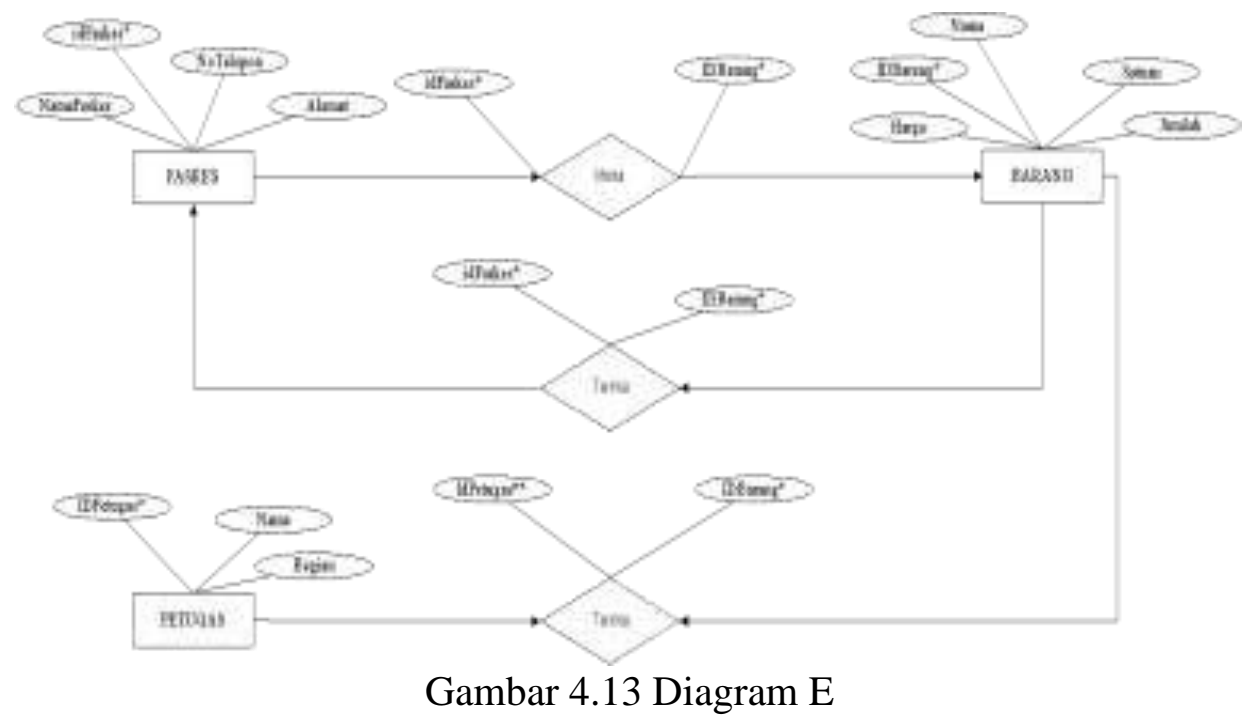

f. Implementasi Program

1. Tampilan Login Program

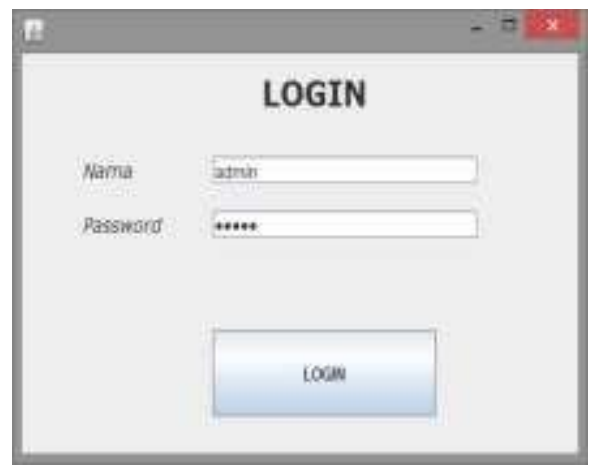

Gambar 4.14 Tampilan Login Program

2. Tampilan Program Data Barang

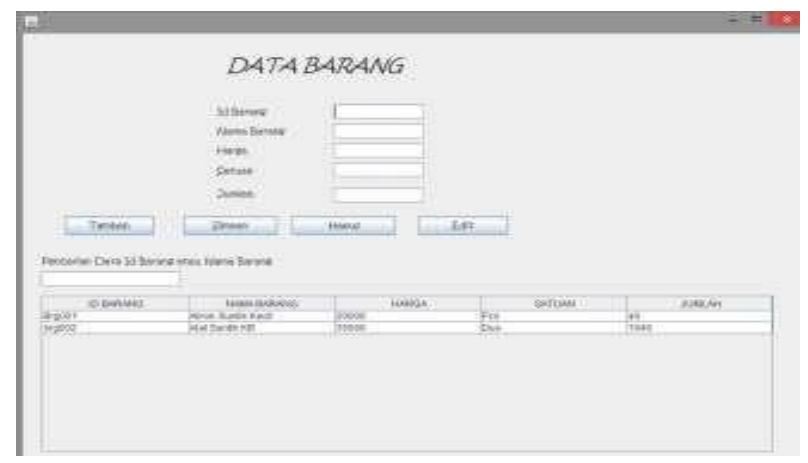

Gambar 4.15 Tampilan Program Data 
JURSISTEKNI (Jurnal Sistem Informasi dan Teknologi Informasi) Vol 2, No.3, September 2020: Hal 45 - 60

ISSN. P: 2715-1875, E: 2715-1883

2. Tampilan Report Berita Acara Penerimaan Barang (BAPB)

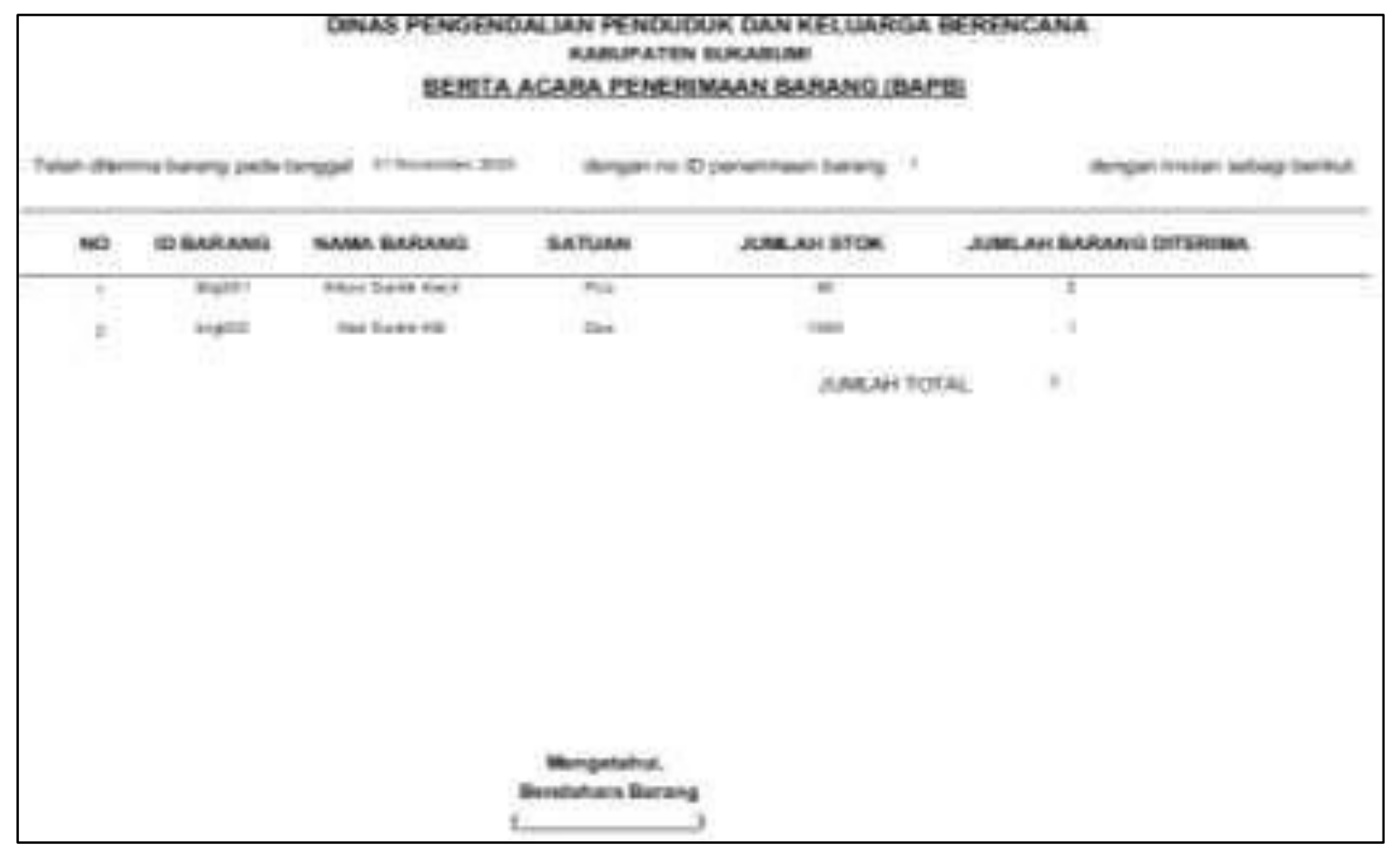

Gambar 4.16 Tampilan Report Berita Acara Penerimaan Barang (BAPB)

\section{KESIMPULAN}

Dalam bab ini dapat ditarik kesimpulan dari materi sebelumnya yang sudah disampaikan, bahwa dengan adanya sistem ini diharapkan :

1. Pendistribusian fasilitas kesehatan di Dinas Pengendalian Penduduk dan Keluarga Berencana Kabupaten Sukabumi melalui sumber daya yang dimilikinya selalu melakukan pemenuhan atas permintaan dan pendistribusian secara merata dan ikut mengawasi sampai lapisan kecamatan atau uptd

2 Perancangan sistem pendistribusian alokon Dinas pengendalian Penduduk dan Keluarga Berencana Kabupaten Sukabumi dibuat dengan sistematis agar semua hal yang berkaitan dengan distribusi ini berjalan sesuai dengan SOP yang berlaku

3. Aplikasi distribusi fasilitas kesehatan di Dinas Pengendalian Penduduk dan Keluarga Berencana ini dibuat dan ditujukan untuk mempermudah serta mengefisiensikan waktu dalam melakukan pembuatan dokumen yang dibutuhkan 
JURSISTEKNI (Jurnal Sistem Informasi dan Teknologi Informasi) Vol 2, No.3, September 2020: Hal 45 - 60

ISSN. P: 2715-1875, E: 2715-1883

\section{DAFTAR PUSTAKA}

[1]. INDRIANTORO, Nur. Pengaruh computer anxiety terhadap keahlian dosen dalam penggunaan komputer. Jurnal Akuntansi dan Auditing Indonesia, 2000, 4.2: 191-209.

[2]. Maulana Ibrahim, T. (2010). Analisis Dan Perancangan Sistem Informasi Perpustakaan Pada PT PUpuk Kujang. [3]. Arif, I. (2003). Konsep dan perencanaan dalam automasi perpustakaan. Yogyakarta: Sagung Seto.

[4]. Saputra, M., Marlinae, L., Rahman, F., \& Rosadi, D. (2015). Program jaminan kesehatan nasional dari aspek sumber daya manusia pelaksana pelayanan kesehatan. KEMAS: Jurnal Kesehatan Masyarakat, 11(1), 32-42.

[5]. Kristanto, A., \& Saputra, D. A. (2011). Perancangan meja dan kursi kerja yang ergonomis pada stasiun kerja pemotongan sebagai upaya peningkatan produktivitas.

[6]. Rahayu, S., Nurhaeni, T., \& Rohmah, M. (2015). Sistem persediaan alat tulis kantor sebagai penunjang pengambilan keputusan bagian logistik di perguruan tinggi raharja. Creative Communication and Innovative Technology Journal, 8(2), 91-101.

[7]. PRAKTIK, L. K., \& BAKTI, A. S. D. M. T. ANALISIS PELAKSANAAN TUGAS SEKRETARIS DALAM PENGELOLAAN SURAT DI DIVISI PENGADAAN PT DIRGANTARA INDONESIA (PERSERO) BANDUNG.

[8]. Larasati, H., \& Masripah, S. (2017). Analisa Dan Perancangan Sistem Informasi Pembelian Grc Dengan Metode Waterfall. Jurnal Pilar Nusa Mandiri, 13(2), 193-198.

[9]. Effendy, A. A., \& Sunarsi, D. (2020). Persepsi Mahasiswa Terhadap Kemampuan Dalam Mendirikan UMKM Dan Efektivitas Promosi Melalui Online Di Kota Tangerang Selatan. Jurnal Ilmiah MEA (Manajemen, Ekonomi, \& Akuntansi), 4(3), 702-714.

[10]. Hasanah, H. (2017). Teknik-teknik observasi (sebuah alternatif metode pengumpulan data kualitatif ilmu-ilmu sosial). At-Taqaddum, 8(1), 21-46.

[11]. Burhansya, M. Z. (2019). Implementasi metode wawancara dalam proses seleksi di PT. Petrosida Gresik: Studi Kasus Pada PT. Petrosida Gresik Jawa Timur (Doctoral dissertation, Universitas Islam Negeri Maulana Malik Ibrahim).

[12]. Darmalaksana, W. (2020). Metode Penelitian Kualitatif Studi Pustaka dan Studi Lapangan. PrePrint Digital Library UIN Sunan Gunung Djati Bandung.

[13]. Trisnadoli, A. (2015). Analisis kebutuhan kualitas perangkat lunak pada software game berbasis mobile. Jurnal Komputer Terapan, 1(2), 1-8.

[14]. Hidayat, R. (2017). Aplikasi Penjualan Jam Tangan Secara Online Studi Kasus: Toko JAMBORE SHOP. Jurnal Teknik Komputer, 3(2), 90-96. 
JURSISTEKNI (Jurnal Sistem Informasi dan Teknologi Informasi) Vol 2, No.3, September 2020: Hal 45 - 60 ISSN. P: 2715-1875, E: 2715-1883

[15]. Nuddin, M. T., \& Fithri, D. L. (2015). Sistem Absensi Asisten Dosen Menggunakan QR Code Scanner Berbasis Android Pada Program Studi Sistem Informasi Universitas Muria Kudus. Prosiding SNATIF, 303-310.

[16]. Handayani, S. (2018). Perancangan sistem informasi penjualan berbasis e-commerce studi kasus toko kun jakarta. ILKOM Jurnal Ilmiah, 10(2), 182-189.

[17]. Widiyanto, W. W. (2018). Analisa Metodologi Pengembangan Sistem Dengan Perbandingan Model Perangkat Lunak Sistem Informasi Kepegawaian Menggunakan Waterfall Development Model, Model Prototype, Dan Model Rapid Application Development (Rad). Jurnal Informa, 4(1), 34-40. 